\title{
Effects of sport activities on increasing preschool children's creativity
}

\author{
Behrooz Jamali $^{\mathbf{a}^{*}}$, Reza Mohammad Kazemi ${ }^{\mathrm{a}}$ and Mehdi Shahbazi
}

${ }^{a}$ Faculty of entrepreneurship, University of Tehran, Tehran, Iran

${ }^{b}$ Faculty of Physical Education and Sport Sciences, University of Tehran, Tehran, Iran

\begin{tabular}{|c|c|}
\hline ART I C L E I N F O & A B S T R A T \\
\hline $\begin{array}{l}\text { Article history: } \\
\text { Received March 25, } 2012 \\
\text { Accepted 11 June 2012 } \\
\text { Available online } \\
\text { June } 152012 \\
\text { Keywords: } \\
\text { TCAM } \\
\text { Preschool children } \\
\text { Creativity } \\
\text { Originality } \\
\text { Fluency } \\
\text { Sport }\end{array}$ & $\begin{array}{l}\text { Torrance tests of creative thinking have been widely used to measure the impact of different } \\
\text { items such as creativity on different groups of children. In this study, we perform an empirical } \\
\text { study to measure the effects of endurance, power-based and flexibility on a group of children's } \\
\text { creativity, originality and flexibility. The study chooses a sample of } 341 \text { from } 2978 \text { preschool } \\
\text { children and distributes a questionnaire among them where } 153 \text { were female and } 188 \text { of them } \\
\text { were male. Cronbach alpha for creativity, originality and fluency were calculated as } 0.814 \text {, } \\
0.822 \text { and } 0.788 \text {, respectively. The results of our study indicate that there are some positive and } \\
\text { meaningful relationship among three components of creativity, originality and fluency before } \\
\text { and after accomplishing test. The impact of test was measured for three types of sport activities } \\
\text { including endurance, power-based and flexibility tests. After applying } 32 \text { sessions of sporting } \\
\text { games, flexibility games represent a mean value of } 32.40 \text {, which is higher than the other two } \\
\text { tests and it maintains meaningful value compared with two other sporting tests of endurance } \\
\text { and power base tests. }\end{array}$ \\
\hline
\end{tabular}

\section{Introduction}

One of the primary objectives of many preschool units in the world is to increase children's creativity through different programs. There are literally many programs developed to measure the relative impact of various programs specified for such programs. Torrance thinking creatively in action and movement thinking creatively in action and movement (TCAM) is one of the most popular techniques (Torrance, 1981). This test has been proven to be successful for investigating many preschool issues and the proposed study of this paper also uses test. During the past three decades, there have been tremendous studies associated with preschool activities. Tegano et al. (1986) performed two tests, built to evaluate ideational fluency through various response modes, administered to 24 middle-class preschool children. The multidimensional stimulus fluency measure (MSFM) needed verbal responses to verbal and visual-tactile stimuli, while thinking creatively in action and movement (TCAM) implemented a nonverbal response mode to verbal and visual-tactile

\footnotetext{
* Corresponding author

E-mail addresses: behrooz_en_ut@yahoo.com (B. Jamali) 
stimuli. Their results indicated construct validity because ideational fluency evaluated via the two instruments was not associated with IQ.

Lloyd and Howe (2003) investigated the relationship between multiple forms of solitary play including solitary-passive, solitary-active and reticence and convergent and divergent thinking. They chose 72 children and used TCAM test to evaluate divergent thinking and the PPVT test and the Picture Completion subtest (WISC-R) to measure convergent thinking. They reported reticent behavior was more strongly negatively related to convergent and divergent thinking than either solitary-active or solitary-passive played. In addition, solitary-active play was more strongly positively associated with divergent thinking. McVearry et al. (2009) investigated the differential impacts of fetal exposure to antiepileptic drugs (AEDs) on cognitive fluency and flexibility in a prospective sample of children.

Maker et al. (2008) studied the relationship between creativity development and implementation of the discovering intellectual strengths and capabilities while observing varied ethnic responses (DISCOVER) curriculum model. They reported that the creativity of all children increased from grades $\mathrm{K}$ to 6 , but children in classrooms of low implementers showed a dip and some "pauses." They also reported that there were some significant differences in scores of children in middle/high and low implementers' classrooms.

Baron et al. (2009) investigated general cognition, attention/working memory, manual coordination/motor dexterity, language, visuomotor, visuospatial, and executive functions in preschoolers born late-preterm (LPT; 34-36 gestational weeks) who needed NICU admission compared with term-born participants. Their results indicated that late-preterm birth tends to related to negative neuropsychological sequelae, although subtle and selective compared to impacts reported for children born at an earlier gestational age. Visuospatial function seems to be especially vulnerable to disruption even at preschool age, and verbal fluency may be useful as an early case of executive dysfunction in childhood. Routine preschool neuropsychological evaluation is recommended to show delay or deficit in LPT children preparing for school entry, and may highlight underlying vulnerable neural networks in LPT children.

Sawyer et al. (2008) investigated whether speech rate, utterance length, and grammatical complexity impacted stuttering-like disfluencies as children became more disfluent at the end of a 1200-syllable speech sample. They also explored the interaction of speech rate, length, and grammatical complexity at the beginning and the end of the speech sample. The purpose of the study was to explain the impact of grammatical complexity and mean length of utterance on disfluent speech, to compare various procedures for evaluating speech rate and to determine why the impacts of articulation rate have been inconclusive. They also discussed some procedures for comparing length, rate, and complexity across a single-speech sample and explained why therapeutic methods, which emphasized shorter utterance lengths, rather than only slower speech rates, were advisable in establishing fluency in preschool children who stutter.

Seçer et al. (2009) investigated whether social skills and problem behavior of preschool children differ according to their being reflective or impulsive or not. Their results impulsive children are less efficient than those who are reflective from the social cooperation and social indicated that interaction points of view while they display more evidences of attention problems/hyperactivity, antisocialism/aggression.

\section{The proposed study}

In this study, we performed our study among 2978 children who were attending preschool educational systems in three different locations in terms of family incomes of city of Tehran, Iran. The sample included 341 people including 153 female and 188 male calculated according to Morgan table and sampling technique. The method for gathering data was based on Torrance tests of creative 
thinking in action and movement (Torrance, 1980, 81a, 81b; Salkind \& Rasmussen, 2007). The test examines four different skills as follows,

- Fluency: The total number of interpretable, meaningful, and relevant ideas generated in response to the stimulus,

- Flexibility: The number of various categories of relevant responses,

- Originality: The statistical rarity of the responses,

- Elaboration: The amount of detail in the responses,

The study considered two groups of control and exam. During the stage of pretest, children were explained about the test and the necessary data were gathered. Next, in two-month period toys were distributed among children and test was repeated again to measure their creativities. In our study, 1323, 1117 and 548 children were selected from 48, 41 and 10 preschools, respectively and $44.8 \%$ of these children were female while $55.2 \%$ were male. Table 1 shows mean, standard deviation and Cronbach alpha for creativity, originality and fluency of the survey.

Table 1

Statistical observation for creativity, originality and fluency

\begin{tabular}{lllcccc}
\hline Variable & 1 & 2 & 3 & Mean & Standard deviation & Cronbach alpha \\
\hline Creativity & 1 & & & 2.89 & 1.669 & 0.814 \\
Originality & $0.66^{* *}$ & 1 & & 1.10 & 1.221 & 0.822 \\
Fluency & $0.48^{* *}$ & $0.47^{* *}$ & 1 & 2.66 & 1.307 & 0.788 \\
\hline
\end{tabular}

As we can observe from the results of Table 1, during the first stage of the survey, all variables maintain meaningful and positive relationships when the level of significance is one percent. Based on the results, we can conclude that in terms of creativity, the children maintained an average creativity. In other words, children had some creativity but they could not extend their abilities, which mean they did not have good originality. Cronbach alphas were all greater than 0.7 , which validate the results of our survey. Table 2 shows similar results we reposted in Table 1 after performing the exam for two months.

Table 2

Statistical observation for creativity, originality and fluency

\begin{tabular}{lllcccc}
\hline Variable & 1 & 2 & 3 & Mean & Standard deviation & Cronbach alpha \\
\hline Creativity & 1 & & & 2.99 & 1.558 & 0.792 \\
Originality & $0.62^{* *}$ & 1 & & 1.19 & 1.229 & 0.776 \\
Fluency & $0.53^{* *}$ & $0.49^{* *}$ & 1 & 2.85 & 1.441 & 0.783 \\
\hline
\end{tabular}

The correlation ratios reported in Table 2, after two months exam execution, indicate that these variables have meaningful and positive relationships when the level of significance is one percent. Based on the results, we can conclude that there are not significant changes on three variables. Table 3 shows details of t-student test results.

Table 3

Statistical results for the mean difference (Sample size $=341$ )

\begin{tabular}{lccccl}
\hline Variable & Mean difference & t-student & df & P-value & Result \\
\hline Creativity & 0.10 & 0.94 & 340 & 0.448 & Reject \\
Originality & 0.09 & 0.89 & 340 & 0.384 & Reject \\
Fluency & 0.19 & 1.13 & 340 & 0.264 & Reject \\
\hline
\end{tabular}


As we can observe from the results of Table 3, none of t-student values represents meaningful value when the level of significance is five percent leading us to reject the null hypotheses. In other words, this test did not have any change on children's' creativity, originality and fluency. The correlation values show that there are meaningful relationships among three variables.

Based on the results we can conclude that children are in average position. In other words, children maintained some capabilities but they could not interpret or develop their skills. In terms of fluency, the mean value shows that children were in good position and in terms of originality, the mean scores indicate that children were in relatively good level. Again, all Cronbach alphas represent relatively high value, which means the questionnaire maintains reliable tool for our study.

\section{The results}

There are three hypothesis associated with the proposed study of this paper.

\subsection{The relationship between sport toys and children's creativity}

To perform a study in this part of our survey, we divided children into two groups and compared the means of these two groups. We have performed pairwise t-test. The null and alternative hypotheses are as follows,

$\mathrm{H}_{0}$ : Sport toys do not increase children's creativity.

$\mathrm{H}_{1}$ : Sport toys increase children's creativity.

Table 4 shows the summary of our test.

Table 4

Mean difference, $t$-student and level of significance $($ Sample size $=341$ )

\begin{tabular}{lccccc}
\hline & \multicolumn{2}{c}{ t-student values before and after exam } & & & \\
\cline { 2 - 3 } Sport games & before & after & df & P-value & Result \\
\hline Endurance Games & 0.988 & 24.927 & 340 & 0.000 & Accept \\
Power-based & 0.922 & 19.244 & 340 & 0.000 & Accept \\
Flexibility Games & 1.12 & 32.407 & 340 & 0.000 & Accept \\
\hline
\end{tabular}

As we can observe from the results of Table 4, all t-student values are meaningful, which means using endurance games, power-based and flexibility games increase children's creativity, significantly. Note that the results of test were valid when the level of significance were one or five percent.

\subsection{The relationship between sport toys and children's originality}

Again, to execute the study in this part of our survey, we divided children into two groups and compared the means of these two groups. We have performed pairwise t-test. The null and alternative hypotheses are as follows,

$\mathrm{H}_{0}$ : Sport toys do not increase children's originality.

$\mathrm{H}_{1}$ : Sport toys increase children's originality.

Table 5 shows the summary of our test. Note that the results of test were tested when the level of significance was one percent. 
Table 5

Mean difference, $\mathrm{t}$-student and level of significance $($ Sample size $=341$ )

\begin{tabular}{llllll}
\hline \multirow{2}{*}{ Sport games } & \multicolumn{2}{l}{ t-student values before and after exam } & & & \\
\cline { 2 - 3 } & before & after & df & P-value & Result \\
\hline Endurance games & 1.21 & 29.927 & 340 & 0.000 & Accept \\
Power-based games & 1.02 & 27.244 & 340 & 0.000 & Accept \\
Flexibility games & 1.19 & 29.407 & 340 & 0.000 & Accept \\
\hline
\end{tabular}

As we can observe from the results of Table 5, all t-student values are meaningful, which means using endurance games, power-based and flexibility games increases children's originality, substantially.

\subsection{The relationship between sport toys and children's fluency}

Again, to execute the study in this part of our survey, we divided children into two groups and compared the means of these two groups. We have performed pairwise t-test. The null and alternative hypotheses are as follows,

$\mathrm{H}_{0}$ : Sport toys do not increase children's fluency.

$\mathrm{H}_{1}$ : Sport toys increase children's fluency.

Table 6 shows the summary of our test. Note that the results of test were tested when the level of significance was one percent.

Table 6

Mean difference, $t$-student and level of significance (Sample size $=341$ )

\begin{tabular}{llllll}
\hline & \multicolumn{2}{l}{ t-student values before and after exam } & & & \\
\cline { 2 - 3 } Sport games & before & After & df & P-value & Result \\
\hline Endurance games & 0.94 & 22.014 & 340 & 0.000 & Accept \\
Power-based games & 0.88 & 21.229 & 340 & 0.000 & Accept \\
Flexibility games & 0.97 & 22.441 & 340 & 0.000 & Accept \\
\hline
\end{tabular}

Once more, we can observe from the results of Table 6 that all t-student values were meaningful, which means using endurance games, power-based and flexibility games increases children's fluency when the level significance is one percent.

In summary, it seems that after applying 32 sessions of sporting games, flexibility games represent a mean value of 32.40. This value is more than mean values obtained from the other two tests and it maintains meaningful value compared with two other sporting tests of endurance and power-based tests. One obvious reason is because this test requires less energy and people get tired less. Endurance game comes in the second position with an average number of 24.92 and one reason is because it needs more concentration. Finally, power-based sport comes in the last position and the main reason could be because it needs more energy. The other observation is that preschool places normally have relatively smaller spaces, which makes it difficult for power-based sports.

\section{Conclusion}

In this paper, we have performed an empirical survey to measure the impacts of endurance, powerbased and flexibility on a group of children's creativity, originality and flexibility. The study distributed a questionnaire among 341 children selected from 2978 preschool children where 153 of them were female and 188 of them were male. The results of our study indicated that there were some positive and meaningful relationship among three components of creativity, originality and fluency 
before and after accomplishing test. The impact of test was measured for three types of sport activities including endurance, power-based and flexibility tests. After applying 32 sessions of sporting games, flexibility games represent a mean value of 32.40, which is higher than the other two tests and it maintains meaningful value compared with two other sporting tests of endurance and power base tests. Finally, power-based sport comes in the last position and the main reason could be because of relatively higher energy it requires. The other observation is that preschool places normally have relatively smaller spaces, which makes it difficult for power-based sports.

\section{Acknowledgment}

The authors would like to thank the officials of preschool children for cordially supporting us to finish this project, successfully. We are grateful to constructive comments on earlier version of this paper, which made it possible for publication.

\section{References}

Baron, I.S., Erickson, K., Ahronovich, M.D., Coulehan, K., Baker, R., \& Litman, F.R. (2009). Visuospatial and verbal fluency relative deficits in 'complicated' late-preterm preschool children. Early Human Development, 85(12), 751-754.

Lloyd, B., \& Howe, N. (2003). Solitary play and convergent and divergent thinking skills in preschool children. Early Childhood Research Quarterly, 18(1), 22-41.

Maker, C.J., Jo, S., Muammar, O.M. (2008). Development of creativity: The influence of varying levels of implementation of the DISCOVER curriculum model, a non-traditional pedagogical approach. Learning and Individual Differences, 18(4), 402-417.

McVearry, K.M., Gaillard, W.D., VanMeter, J., \& Meador, K.J. (2009). A prospective study of cognitive fluency and originality in children exposed in utero to carbamazepine, lamotrigine, or valproate monotherapy. Epilepsy \& Behavior, 16(4), 609-616

Tegano, D.W., Moran III, J.D., \& Godwin, L.J. (1986). Cross-validation of two creativity tests designed for preschool children. Early Childhood Research Quarterly, 1(4), 387-396.

Torrance, E. P. (1980). Growing Up Creatively Gifted: The 22-Year Longitudinal Study. The Creative Child and Adult Quarterly, 3, 148-158.

Torrance, E. P. (1981a). Predicting the creativity of elementary school children (1958 80) and the teacher who "made a difference." Gifted Child Quarterly, 25, 55-62.

Torrance, E. P. (1981b). Empirical validation of criterion referenced indicators of creative ability through a longitudinal study. Creative Child and Adult Quarterly, 6, 136-140.

Salkind, N. J. \& Rasmussen, K. (2007). Encyclopedia of Measurement and Statistics. SAGE. ISBN: 9781412916110.

Sawyer, J., Chon, H., \& Ambrose, N.G. (2008). Influences of rate, length, and complexity on speech disfluency in a single-speech sample in preschool children who stutter. Journal of Fluency Disorders, 33(3), 220-240.

Seçer, Z., Çeliköz, N., Koçyiğit, S., Seçer, F., \& Kayılı, G. (2009). Social skills and problem behaviour of children with different cognitive styles who attend preschool education. Procedia Social and Behavioral Sciences, 1(1), 1554-1560. 